\title{
PEMIKIRAN MISTISISME ANNEMARIE SCHIMMEL
}

\author{
Vmar Faruq Thofir \\ STAI Zainul Hasan Genggong Probolinggo \\ Telp.085726917057 email: banitohir@gmail.com
}

\begin{abstract}
Sufism is the unique esoteric way to close to Allah as The Creator of this universe. Sufism teaches its scholars to purify their souls from the sins or something prohibited by Allah, and fulfill them with a good actions and characters. Sufism also coaches its scholars to base their actions with love to Allah, since love to Allah will guide scholars to love all Allah's creations such as like human, animal, tree, and all inside this universe. Loving Allah also drags people to be easy in obeying Allah's commandments where without love, people possibly hard to apply them. In all these terms, Sufism understood by its insiders (scholars) as a doctrine to be closer to Allah that must be obeyed. In opponent with these insiders, the outsiders acknowledge Sufism is mere tenet that not must be obeyed totally, but can be absorbed and adopted partly. Annemarie Schimmel is one of outsiders Sufism. Schimmel adopted al Rumi's Sufism taught without becoming Moslem who al Rumi becomes. Schimmel only looks Sufism from the outside. She judges Sufism as a mystical taught which not only found in Islam, but also in other religions which have a mystical method. That's why she felt not need to be a Moslem, even she adopted and applied al Rumi's taught, because she did not view al Rumi as a Moslem teacher but a mystical teacher. Even Schimmel was not a Moslem, but, her study to Sufism should be appreciated, because outsider typically objective in their study.
\end{abstract}

Tasawuf adalah metode esoteris yang dipakai untuk bertaqarrub kepada Allah, Sang Pencipta Alam. Tasawuf mengajarkan para penganutnya untuk menyucikan jiwa (tazkiyah al nafs) dari dosa atau sesuatu yang dilarang Allah, dan mengisinya dengan perilaku dan sifat yang baik. Tasawuf juga mengarahkan para penganutnya untuk mendasari segala perbuatan mereka dengan rasa cinta kepada Allah. Hal itu akan memandu mereka untuk menyayangi ciptaan Allah 
yang lain, seperti sesama manusia, hewan, tumbuh-tumbuhan, dan semua ciptaan Allah yang lain di alam semesta ini. Cinta kepada Allah akan membuat orang mudah dalam melakukan perintah-perintah-Nya, di mana tanpa rasa cinta, orang akan merasa keberatan. Dalam konteks ini, tasawuf dipahami oleh para penganutnya (insider) sebagai doktrin yang wajib dilakukan untuk lebih mendekatkan diri kepada-Nya. Sebaliknya, outsider, orang yang bukan penganut tasawuf, menganggap tasawuf hanyalah sekedar ajaran yang tidak harus dipatuhi sepenuhnya, melainkan dapat diabsorpsi dan diadopsi sebagiannya saja. Salah satu dari outsider ini adalah Annemarie Schimmel. Schimmel dalam pemikiran tasawufnya banyak mengadopsi pemikiran al Rumi, meski dia tidak menjadi muslim seperti al Rumi. Schimmel hanya melihat tasawuf dari sisi luarnya (outside) saja. Schimmel menganggap tasawuf sebagai ajaran mistis yang tidak hanya ditemukan di dalam agama Islam saja, melainkan juga di beberapa agama yang lain. Oleh karena itulah, dia merasa tidak perlu menjadi muslim meski dia mengadopsi pemikiran tasawuf al Rumi, karena Schimmel tidak melihat al Rumi sebagai guru dalam persoalan agama Islam, melainkan guru dalam hal mistisisme. Meski Schimmel bukanlah seorang muslim, namun kajian-kajiannya dalam bidang tasawuf patut diapresiasi karena biasanya, outsider cenderung objektif.

Key words: sufism, outsider, annemarie schimmel

\section{Pendahuluan}

Pada dasarnya tasawuf adalah ekspresi seseorang dalam aktifitas keberagamaan. Ketika "ajaran" fiqh, kalam dan filsafat dirasa tak lagi mampu membawa manusia ke dalam tujuan hakiki beragama, maka tidak pelak tagi, tasawuf dengan jalan "pencarian" yang mengedepankan dimensi batin dan spiritual, mulai banyak dilirik (Arifin, dkk, 1996: 36).

Sebagai asumsi dasar, tasawuf mengajarkan bahwa realitas Tuhan tidak dapat diketahui oleh metode-metode logis atau rasionalis yang cenderung eksoteris. Reallitas Tuhan harus didekati melalui cinta, karena cinta membawa pada penghayatan keagungan dan rahmat Ilahi, dimana perasaan intimasi yang esoteris bersama-Nya bisa tercapai (Ernest, 2002: 509-510). Dari perspektif kaum sufi, sepanjang "engkau" masih "dirimu sendiri", engkau tidak akan pernah mengenal Tuhan, karena selubung terbesar yang menghalangi engkau dengan realitas Tuhan adalah "dirimu". Hanya api cinta ilahi yang dapat membakar egosentrisitas. Lebih-lebih, cinta ilahi muncul secara spontan, ia tidak dapat dipelajari melalui kajian (Nurbakhsh, 2002: 3).

Pada saat cinta ilahi menguasai alam pikiran, seolah terbuka secara terang benderang semua hakikat kebenaran yang dulunya semu. Orang yang 
telah sampai pada posisi ini sudah tidak mementingkan "materi" keduniawian lagi, karena yang terpenting baginya adalah Sang Kekasih, cinta keabadian, cinta ilahi (Haeri, 2003: 119-126). Sufi yang sudah sampai pada tingkatan cinta ini tidak ingin dipuji lagi, atau jika dipuji pun, tidak pernah berubah, dan bila dicaci maki pun tidak pernah berubah, karena semuanya hanyalah untuk Allah (Anwar, 2009: 139). Bahkan menurut M. Amin Syukur, Rabiah Adawiyah, yang masyhur dengan pengalaman cinta kepada Tuhan, mampu memalingkan diri dari segala sesuatu selain Tuhan. Dalam doanya, ia tidak meminta dijauhkan dari neraka dan tidak pula meminta dimasukkan ke surga. Yang ia pinta adalah dekat dengan Tuhan (Syukur, 2012: 53)

Cinta yang mewarnai seluruh alam pikir dan tindakan, membuat sufi selalu memikirkan-Nya, hingga keluarlah prosa-prosa puitis yang indah dan narasi-narasi bersajak yang menunjukkan indikasi bahwa hatinya sedang diselimuti suatu rasa yang "irrasional" kepada-Nya. Syair-syair cinta, prosa-prosa bersajak, atau pun puisi-puisi romantis tersebut merupakan ekspresi alami yang muncul karena perasaan cinta yang mendalam (Ernest, 2002: 509-512).

Karya-karya dalam bentuk kalimat bersajak serta puitis tersebut memiliki daya tarik tersendiri bagi penerus sufi (insider) dan para pengkaji ketasawufan (outsider) untuk dipahami lebih dalam. Bagi para penerus sufi, cinta ilahi yang tersirat dalam sajak-sajak puitis tersebut merupakan ajaran dari sang guru yang patut diikuti, sedangkan bagi para pengkaji yang bukan pelaku tasawuf, ajaran cinta ilahi tersebut harus disampaikan ke publik yang merasa kehausan terhadap nilai-nilai spiritual yang mungkin tergerus semangat modernitas. Para pengkaji outsider Tasawuf ini ada yang dari Timur (muslim) dan juga dari Barat (orientalis). Para outsider Barat yang mengkaji keunikan tasawuf ini sangat banyak sekali, diantaranya Annemarie Schimmel, Bruce B. Lawrence, Herbert Mason, Gerhard Bowering, William C. Chittick, John Cooper, Carl W. Ernest (Lewisohn, 2002: iv-v), dan beberapa orientalis lain, namun makalah ini hanya akan membahas tentang Annemarie Schimmel (selanjutnya pakai Schimmel saja), karena, dibanding yang lain, meski dia seorang orientalis, bahkan Protestan, Schimmel lebih familiar di tengah-tengah literatur tasawuf muslim kekinian, bahkan tidak jarang Annemarie Schimmel diminta untuk memberikan "Kata Pengantar" dalam beberapa buku tasawuf yang bahkan disusun oleh muslim (Lewisohn, 2002: i-iii).

Menurut Schimmel, tasawuf yang mengajarkan cinta ilahi, merupakan media aktualisasi manusia yang paling ideal. Meskipun di banyak sisi, tasawuf dituduh sebagai 'pembunuh otoritas akal', namun di sisi yang lain, 
keberhasilannya membangun kepribadian manusia serta ide-idenya tentang cinta kasih, perdamaian, kesederhanaan, penyucian jiwa dan solidaritas memberi andil yang tidak sedikit dalam mewujudkan kehidupan yang lebih baik. Konsep cinta dalam hal ini merupakan unsur penting dalam perjalanan pencarian kesejatian manusia melalui jalan tasawuf (Ernest, 2002: 509-512). Pernyataan senada juga disampaikan Annmarie Schimmel pada saat memberikan ceramah di Aula Perpustakaan Nasional Jakarta pada tanggal 25 Februari 2002 (Burhani, 2002: v).

Orang yang benar-benar mencintai Tuhan mengetahui bahwa dalam penderitaan pun, ada tangan Tuhan yang dia rasakan, dan dia yakin bahwa apapun yang menimpadirinya adalah yang terbaik baginya, karena Tuhan Maha Tahu atas apa yang terbaik bagi pertumbuhan jiwa dan penucian ruh (Schimmel, 1997: 10-11; Rabbani, 1995: 223-233).

Tulisan ini akan membahas tentang biografi Annemarie Schimmel, ketertarikannya terhadap tasawuf yang konsepnya lahir dari Islam, namun tidak membuatnya masuk Islam. Fokus kajiannya hanya para sufi yang terkenal mengajarkan tasawuf dengan puisi.

\section{Biografi Annemarie Schimmel}

Annemarie Schimmel lahir pada tanggal 7 April 1922 di Erfurt, Jerman, sebagai anak tunggal dari orang tua dengan berbudaya kelas menengah, yang membesarkannya dalam suasana penuh dengan sastra dan puisi (Haskins, 1993: 1). Melewatkan dua kelas di sekolah menengah, ia mulai studinya di Universitas Berlin pada musim gugur tahun 1939 pada usia tujuh belas tahun. Gurunya yang paling berpengaruh dan memberi inspirasi adalah Hans Heinrich Schaeder. Schaeder menyarankan agar dia mempelajari puisi dan karya Jalaluddin Rumi. Dia secara intuitif memahami ide-ide yang terkandung dalam puisi ini dan tidak pernah melepaskannya lagi (Haskins, 1993: 2).

Pada bulan Oktober 1941, ketika berusia 19 tahun, dia meraih gelar doktor dalam bidang Bahasa dan Peradaban Islam dengan disertasi tentang Mesir abad pertengahan. Tak lama kemudian, ia diterima oleh Departemen Luar Negeri pada unit decoding. Dia terus bekerja pada proyek-proyek ilmiah dalam waktu luangnya (Haskins, 1993: 7-10).

Schimmel hidup pada saat Jerman sedang dalam penjajahan dan suatu ketika Schimmel tertangkap dan digiring ke Marburg. Pada tanggal 8 Mei 1945 hari perang berakhir dan mereka segera mendirikan sebuah «kamp universitas,» dan memberikan ceramah pertamanya pada hal hal Islam. Pada tanggal 12 
Januari 1946, ia memberikan kuliah perdananya tentang «Perwakilan Utama Tasawuf Islam» pada usianya yang ke dua puluh tiga (Haskins, 1993: 13-15). Pada tahun 1951, ia meraih gelar doktor yang kedua dalam Sejarah AgamaAgama yang diberikan oleh Fakultas Teologi Protestan di Marburg, dengan judul penelitian tentang cinta mistis dalam Islam (Haskins, 1993: 9-11).

Pada awal tahun lima puluhan Schimmel membuat beberapa perjalanan ke Turki. Pada tahun 1953, saat dia di Ankara, ia memberikan kuliah publik pertama di Turki (Tim Penerbit Pustaka Sufi, 2002: vii-viii). Beberapa lama kemudian Fakultas Teologi menawarinya kursi kosong untuk mengajar dalam bidang Sejarah Agama.

Schimmel sangat mengapresiasi Fakultas Teologi Islam tersebut yang hendak menjadikannya sebagai pengajar, lantas dia bertanya, seolah menantang, apakah ada sebuah fakultas teologi Protestan Jerman yang berani menunjuk seorang wanita muslim untuk guru besar? Bahkan dalam sambutannya pada Kongres Internasional tentang Sejarah Agama di Roma pada Agustus 1990, Annemarie Schimmel menyampaikan kekecewaannya terhadap kajian tentang Sejarah Agama yang selalu dikaji dari sudut pandang yang menguntungkan Barat. Menurutnya, juga ada cendekiawan di Asia yang ikut memberi sumbangan besar terhadap sejarah atau fenomenologi agama, seperti Buddhisme, Konfusianisme, Shinto, bahkan Islam. Namun sayang, sikap para sarjana Barat tampaknya masih banyak dipengaruhi oleh latar belakang "biblikal" dan pendekatan "klasik" terhadap keilmuan (Schimmel, 1996: 15).

Schimmel tinggal di Turki selama lima tahun (1954-1959) dan membuatnya "terobsesi" dengan Rumi. Melalui bukunya yang sudah diterjemahkan ke dalam bahasa Indonesia dengan judul Dunia Rumi: Hidup dan Karya Besar Penyair Sufi, Schimmel menggiring ke imajinasi masa silam tentang Konya dengan segala kultur dan peradabannya, jalan-jalan menuju Konya, ekspresi-ekspresi puitis Rumi, dan perasaan tentang Konya. Schimmel seolah sangat meyakinkan bahwa ia tidak hanya sekedar pernah ke daerah itu, tapi juga mengerti sesuatu yang "inti" di daerah (Konya) itu (Tim Penerbit Pustaka Sufi, 2002: vii).

Selain Rumi, tokoh favorit Schimmel yang lain adalah Muhammad Iqbal, yang merupakan pemikir Indo-muslim dan penyair, yang juga mewarnai tulisan-tulisannya selama ini. Atas desakan temannya di Turki, dia menghasilkan terjemahan beranotasi buku rohani terkenal Iqbal. Hal ini menyebabkan dirinya pada tahun 1958 mengunjungi Pakistan yang merupakan titik tolak dari suatu kepentingan penelitian baru yang akhirnya membawanya ke Universitas Harvard (Schimmel, 2002: 3-14). 
Pada bulan Agustus 1965, pada kunjungan pertamanya ke Amerika Serikat untuk menghadiri Kongres ke-11 Asosiasi Internasional untuk Sejarah Agama di Claremont, California, Schimmel didekati oleh Harvard Wilfred Cantwell Smith, yang mengatakan bahwa terdapat dana besar yang telah diberikan kepada Universitas Harvard untuk mengkaji dua penyair besar Urdu, Mir dan Ghalib, dan menyuruh menerjemahkan karya mereka ke dalam bahasa Inggris dengan gaya bahasa puitis. Namun Schimmel menolak tawaran tersebut, karena dia mengklaim bahwa dirinya tidak ahli dalam bahasa Urdu dan tidak siap bergabung dalam proyek itu. Tapi, Smith dan temannya yang lain di Harvard membujuknya dengan tabah, hingga akhirnya Schimmel mau bergabung dalam penelitian tersebut (Haskins, 1993: 10-15).

Pada musim semi tahun 1967 dia mulai di Harvard sebagai Dosen pada bidang Budaya Indo-Muslim, dan pada tahun 1970 ia diangkat sebagai profesor penuh. Annemarie Schimmel mengajar hanya pada musim semi saja dan hampir setiap tahun ia pergi ke Pakistan di musim gugur. Meskipun dia hanya mengajar selama jangka waktu musim semi, tapi dia sangat peduli dengan murid-muridnya, dan mereka pun memujanya, berdiri kagum, bahkan mereka juga mempercayainya dan meminta nasihatnya dalam hal hal pribadi. Schimmel merupakan dosen yang banyak dicari, dengan gaya penyampaiannya yang khas, yaitu menggenggam tasnya dengan kedua tangan, menutup matanya, dan berbicara untuk persis jumlah waktu yang diberikan padanya. Annemarie Schimmel menyatakan bahwa dia bisa kuliah tanpa naskah dalam bahasa Jerman, Inggris dan Turki, atau dengan naskah (dan mata terbuka) dalam bahasa Prancis, Arab, Persia dan Urdu (Haskins, 1993: 16).

Pada tahun 1992 ia pensiun dari Harvard dan kembali ke Bonn. Dalam kesehariannya, dia menghabiskan hidupnya dengan kegiatan perkuliahan dan menulis. Pada tanggal 15 Oktober 1995, ia menerima Hadiah Perdamaian bergengsi dari Asosiasi Buku Perdagangan Trade Jerman untuk menghormati prestasinya dalam menghasilkan pemahaman Timur-Barat (Burhani, 2002: 16).

Pada tanggal 26 Januari 2003, Schimmel meninggal dunia karena komplikasi setelah operasi. Schimmel meninggalkan seorang anak yang sangat dicintai, sepupu dan keluarganya, yang sekarang tinggal di California dan New Jersey, serta sejumlah besar teman, kolega, mahasiswa, yang akan selalu mengenang karya-karyanya dengan penuh sukacita dan kekaguman (Haskins, 1993: 19). 


\section{Karir Akademik}

Annemarie Schimmel lahir sebagai penganut agama Protestan dan memiliki orang tua yang berbudaya kelas menengah di Erfurt, Jerman (Rabbani, 1995: 222-223). Ayahnya, Paulus, adalah seorang pekerja pos dan ibunya, Anna, memiliki usaha keluarga dengan koneksi ke perdagangan dan pelayaran internasional. Schimmel selalu mengenang ayahnya sebagai "teman bermain indah penuh menyenangkan". Ibunya membuatnya merasa dia adalah anak dari impian dan rumahnya penuh dengan puisi dan sastra, meskipun keluarganya bukanlah lulusan sastra (Haskins, 1993: 3-5).

Schimmel mulai belajar di Universitas Berlin pada tahun 1939 pada usia 17 tahun, selama periode Nazi Jerman. Ia menerima gelar doktor dalam Bahasa dan Peradaban Islam pada usia sembilan belas. Pada usia 23, ia menjadi guru besar bahasa Arab dan studi Islam di Universitas Marburg, Jerman pada tahun 1946. Kemudian ia meraih gelar doktornya yang kedua dalam sejarah agama-agama pada tahun 1954 (Haskins, 1993: 7-9).

Titik balik dalam hidupnya datang pada 1954 ketika dia diangkat menjadi Profesor Sejarah Agama di Universitas Ankara (Turki). Di sana ia menghabiskan lima tahun mengajar di Turki dan membenamkan dirinya dalam tradisi budaya dan mistis Negara (Rabbani, 1995: 222-223).

Schimmel merupakan anggota fakultas di Universitas Harvard 1967-1992 dan menjadi Profesor Emerita Budaya Indo-Muslim saat pensiun. Dia juga seorang profesor kehormatan di Universitas Bonn. Ia menerbitkan lebih dari 50 buku tentang literatur Islam, mistisisme dan budaya, yang diterjemahkan dari bahasa Persia, Urdu, Arab, Sindhi dan Turki dalam bentuk puisi dan sastra ke dalam bahasa Inggris dan Jerman (Burhani, 2002: v).

Berkat karyanya tentang Islam, tasawuf atau mistisisme dan Muhammad Iqbal, pemerintah Pakistan akhirnya memberikan penghargaan sipil tertinggi kepadanya yang dikenal dengan Sitara e Imtiaz (Star of Excellence) dan Hilal e Imtiaz (Crescent of Excellence). Selain itu, Schimmel juga mendapatkan penghargaan Leopold Lucas, hadiah dari Fakultas Evangelisch-Theologische dari Universitas Tübingen, dan pada tahun 1995 mendapatkan penghargaan bergengsi, yaitu hadiah perdamaian perdagangan buku Jerman (Rabbani, 1995: 222-223).

Adapun di antara karya-karya Schimmel adalah As Through A Veil: Mystical Poetry in Islam, New York: Columbia University Press, 1982; And Muhammad Is His Messenger: The Veneration of the Prophet in Islamic Piety, The University of North Carolina Press, 1985; Anvari's Divan: A Pocket Book for Akbar, 1994; A Dance of Sparks: Imagery of Fire in Ghalib's Poetry; A Two-Colored Brocade: The 
Imagery of Persian Poetry, University of North Carolina Press, 1992; Deciphering the Signs of God: A Phenomenological Approach to Islam, Gifford Lectures, 1992; Gabriel's Wing: Study into the Religious Ideas of Sir Muhammad Iqbal; Mystical Dimensions of Islam, North Carolina Univ. Press, 1975; Introducción al Sufismo, 2007; Rumi's World: The Life and Works of the Greatest Sufi Poet; Im Reich der Grossmoguls: Geschichte, Kunst, Kultur, 2000; The Empire of the Great Mughals: History, Art and Culture, Ed. Reaktion books Ltd, London, 2004; The Triumphal Sun: A Study of the Works of Jalaloddinn Rumi, London: East-West Pub., 1980; Islamic literatures of India, Wiesbaden : O. Harrassowitz, 1973; Mohammad Iqbal, poet and philosopher: a collection of translations, essays and other articles, Karachi, Pakistan-German Forum, 1960; Classical Urdu literature from the beginning to Iqbal, Wiesbaden : O. Harrassowitz, 1975; Islam: An Introduction, Albany: State University of New York Press, 1992; We believe in one god: the experience of God in Christianity and Islam, 1979; Calligraphy and Islamic Culture, New York University Press, (1990); Islamic Names: An Introduction (Islamic Surveys), Edinburgh University Press, England, 1990; My Soul is a Woman, The Feminine in Islam, 1997; Make A Shield From Wisdom : Selected Verses from Nasir-i Khusraw's Divan, 2001; Das Mysterium der Zhal, ed. Eugen Diederichs Verlag, Munich, (1983) (Tim Penerbit Pustaka sufi, 2002: vii-1x).

\section{Konsep Tasawuf Menurut Annemarie Schimmel}

Sebelum masuk pada pembahasan bagaimana Schimmel (outsider) menggambarkan tasawuf, penyusun akan menggambarkan bagaimana tasawuf berkembang dalam pikiran para sufi dan pengamat insider tasawuf terlebih dahulu.

Kata tasawuf berasal dari bahasa Arab, yaitu tashawwuf. Kata tashawwuf

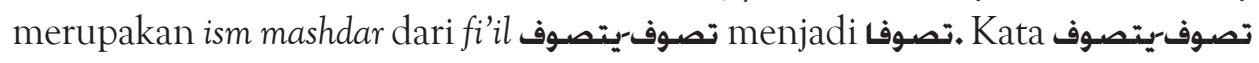
merupakan فعل مزيد بحسرفين yaitu "tâ" "dan "mudhâ'af," yang sebenarnya berasal

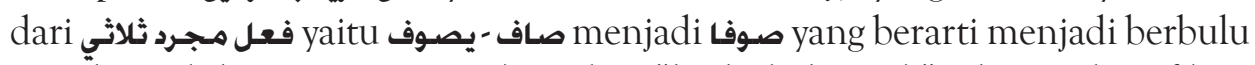
yang banyak (Yunus, 1972: 224). Makna "berbulu banyak" sebagai identifikasi sufi klasik yang pakaiannya terbuat dari bulu domba (Anwar, 2009: 11).

Sebenarnya para pengkaji berbeda pendapat tentang asal kata tasawuf, disamping ada yang berpendapat seperti penjelasan di atas, ada juga yang mengatakan berasal dari kata al shuffah, al shaff, al shufânah dan al shûf (Musthofa, 2002: 201). Namun H. M. Amin Syukur menjelaskan bahwa asal kata tasawuf lebih tepat dikatakan berasal dari kata al shûf, hal ini karena ahli tasawuf biasanya menggunakan pakaian dari bulu domba (Syukur, 2012: 
7-11). Tasawuf adalah ajarannya, sementara pelakunya disebut mutashawwif yang dalam bahasa Indonesia disebut sufi, sebagai sifat bagi orang yang biasa menggunakan kain shêf (Umarie, 1996: 9).

Jika secara etimologis saja sudah terdapat perbedaan, dapat dipastikan, dalam pengertian terminologis juga akan terdapat banyak perbedaan. Menurut Sahal Ibnu Abdillah, sebagaimana dikutip Rosihon Anwar, tasawuf adalah menyedikitkan makan, sungguh-sungguh dalam beribadah kepada Allah, dan lari dari manusia (Anwar, 2009: 16). Melalui perspektif yang lebih inklusif dan sosialis, Haidar Bagir dengan konsep tasawuf positifnya mengatakan bahwa sufi yang baik adalah sufi yang mementingkan amal amal sholeh untuk memperbaiki kualitas lingkungan hidup. Ia adalah orang yang sehat, giat bekerja, mencari nafkah bagi kehidupan dunianya. Ia boleh kaya, tetapi kekayaannya digunakan secara proporsional untuk dirinya, keluarganya dan kegiatan-kegiatan pemberdayaan umat yang tidak berdaya dan lemah (Bagir, 2002: xxiv-xxv).

Tasawuf adalah ajaran Islam yang membina akhlak manusia di atas bumi ini, agar tercapai kebahagiaan dan kesempurnaan hidup lahir dan bathin, dunia dan akhirat. Sufi adalah orang yang memiliki sikap-sikap mulia dan menghindari sikap-sikap tercela, sanggup menderita lapar dan dahaga, tetapi bila memperoleh rizki tidak lekat di dalam hatinya (zuhud) (Syukur, 2012: 18-19).

Lebih jauh lagi, zuhud dapat dibagi menjadi dua, sebagai maqâm dan akhlâq. Sebagai maqâm, zuhud berarti hilangnya kehendak, kecuali berkehendak untuk bertemu dengan Tuhan. Dunia dianggap penghalang (hijâb) bertemunya seseorang dengan Tuhan dan karena itu ia dianggap sesuatu yang berlawanan arah (dikotomi) dengan-Nya. Sebagai akhlâq, zuhud dapat diwujudkan dalam kehidupan yang sederhana, wajar, integratif, inklusif dan aktif dalam berbagai kehidupan di dunia ini, sebagaimana telah dicontohkan Rasulullah saw. dan shahabat-shahabatnya (Syukur, 1997: v).

Tasawuf adalah bagian dari al syarî'ah al islâmiyah, yakni wujud dari ihsân, salah satu dari tiga kerangka ajaran Islam yang lain, yaitu îmân dan islâm. Oleh karena itu, perilaku sufi harus tetap berada dalam kerangka syari'at Islam. Al Qusyairi sebagaimana dikutip M. Amin Syukur mengatakan: "Seandainya kamu melihat seseorang yang diberi kemampuan khusus (karâmah), sehingga ia bisa terbang di angkasa, maka jangan terburu tergiur kepadanya, sehingga kamu melihat bagaimana dia menjalankan perintah, meninggalkan larangan menjaga hukum yang ada" (Syukur, 2004: 4). 
Ihsân meliputi semua tingkah laku muslim, baik tindakan lahir maupun tindakan batin, dalam ibâdah maupun muâmalah, sebab ihsân adalah jiwa dari îmân dan islâm. Îmân sebagai pondasi yang ada pada jiwa seseorang dari hasil perpaduan antara ilmu dan keyakinan, penjelmaannya berupa tindakan badâniyah (ibâdah lahîriyah) disebut Islam. Perpaduan antara îmân dan islâm pada diri seseorang akan menjelma sebagai pribadi dalam bentuk akhlâq al karîmah atau disebut ihsân (Syukur, 2004: 5).

Syekh Fadhlalla Haeri mengatakan bahwa tasawuf harus dimulai dari praktek-praktek lahir, dalam rangka untuk memperkuat, mengembangkan, dan memperkaya keadaan (hâl) kesadaran bathin. Artinya, tidak benar jika dikatakan bahwa tasawuf harus menghindari urusan dunia dengan sangat fokus pada urusan akhirat saja (Haeri, 2003: 5-6).

Pernyataan-pernyataan tersebut adalah definisi tentang tasawuf yang dilihat dari sudut pandang insider (sufi/Muslim), yang bisa jadi bertentangan dengan pandangan outsider (orientalis). Para insider lebih mengerti tentang alur tasawuf secara utuh karena memang merupakan pelaku tasawuf, sementara outsider dianggap kurang begitu memahami tasawuf secara detil, karena hanya sebagai pengamat luar saja (Rabbani, 1995: 222-223).

Menurut Schimmel, tasawuf sama dengan mistik. Hal itu terlihat dari tulisan-tulisan tasawufnya yang selalu menggunakan terma mistisisme, bukan terma sufisme, apalagi terma tashawwuf, meski dia mengakui ada beberapa orang yang menggunakan terma sufisme untuk menjelaskan tasawuf (Schimmel, 2000: 1).

Munculnya kata mistik diambil dari kata Yunani myein yang berarti "menutup mata." Mistik adalah sesuatu yang mengandung kemisteriusan yang tidak bisa dicapai dengan cara-cara biasa atau usaha intelektual. Mistik disebut "arus besar kerohanian yang mengalir dalam semua agama." Dalam artinya yang paling luas, mistik bisa didefinisikan sebagai kesadaran terhadap Kenyataan Tunggal, yang mungkin disebut kearifan, Cahaya, dan Cinta (Schimmel, 2000: 1-2).

Schimmel mengatakan bahwa tasawuf yang sampai ke Eropa pada abad ke-16 dan ke-17 adalah tasawuf yang dikenalkan oleh para pelancong dan pengelana yang mengunjungi Timur Tengah yang membawa pulang keteranganketerangan tentang upacara-upacara darwis, sufi yang kumuh, miskin, dan bajunya penuh dengan tambalan jahitan (Schimmel, 2000: 24-25; Baldick, 2002: 195-197). Keadaan sufi yang seperti ini menjadi daya tarik tersendiri bagi orang Eropa. Oleh karena itulah, mereka banyak yang melakukan kajian 
mendalam tentang perilaku misterius (unik) sufi ini yang mereka sebut dengan mistik (Schimmel, 2005: 30-36).

Diantara para orientalis, ada yang menyebut istilah tasawuf dengan sufisme dan mistisisme. Contohnya seperti Herbert Mason yang menggunakan istilah sufisme dalam Hallaj dan Madzhab Sufisme Baghdad, Gerhard Bowering dalam Gagasan tentang Waktu dalam Sufisme Persia, dan Bernd Radtke dalam Konsep Wilayah dalam Sufisme Awal (Lewisohn, 2002: 103-120, 249-288, dan 563-578). Sedangkan yang menggunakan istilah mistisisme adalah Leonard Lewisohn dalam Pencarian Pembinasaan: Imajinalisasi dan Kematian Mistik dalam Tamhîdât Ain al Qudât Hamazânî (Lewisohn, 2002: 343-399).

Istilah sufisme merupakan terma yang lebih tepat dibanding dengan penggunaan istilah mistisisme, karena tasawuf sesungguhnya tidak hanya berisi tentang perilaku-perilaku mistik saja, seperti cerita Nabi Yunus dengan ikan paus atau al Hallaj yang bisa menyatu dengan Tuhan, melainkan juga anjuran untuk hidup bersama, berbagi dan saling menghormati, sebagaimana tasawuf akhlâqî al Ghazali. Dalam konteks tasawuf, al Ghazali menganut tasawuf yang bercorak psiko-moral, yang mengutamakan pendidikan moral sesuai dengan naluri alamiah Islam. Al Ghazali mengusung konsep ma'rifah dalam batas pendekatan diri kepada Allah (taqarrub bi Allâh) tanpa diikuti penyatuan dengan-Nya (al Ghazali, tt.: 96). Sedangkan kata sufisme adalah faham yang dinisbahkan kepada sufi yang dulunya terbiasa menggunakan kain wol (Rabbani, 1995: 115-1164).

Sebagai outsider, bahkan orientalis, Annemarie Schimmel menyamakan tasawuf dengan ilmu mistik. Oleh sebab itulah, ia menganggap tasawuf juga terdapat dalam dunia Kristen, Yahudi, Budha, Konfusianisme, Shinto, dan beberapa agama yang lain, karena semua agama dan kepercayaan itu memiliki ajaran mistik. Berdasarkan alur berpikir seperti inilah, Schimmel menganggap tasawuf sebagai ilmu mistiknya Islam (Schimmel, 2000: 4).

Menurut hemat penyusun, ini adalah jawaban kenapa Schimmel tidak pindah keyakinan menjadi Muslim, melainkan tetap sebagai penganut Protestan yang setia meski telah lama mengkaji bahasa dan peradaban Islam, mengajar tasawuf di berbagai universitas, bahkan telah lama meneliti tentang kajian tasawuf. Hal itu disebabkan oleh keyakinannya bahwa tasawuf adalah bagian dari ajaran tentang mistik yang tidak hanya terdapat dalam agama Islam, tetapi juga dalam beberapa agama lain, termasuk agama keyakinannya, Protestan. Bagi Schimmel, semua agama mengajarkan kemistikan, dalam arti kesadaran terhadap Kenyataan Tunggal, yang mungkin disebut kearifan, Cahaya, dan 
Cinta (Schimmel, 2000: 1-2). Jika semua agama memiliki ajaran kemistikan, maka semua agama memiliki ajaran tasawuf (Khan, 2002: 125-128).

Namun pendapat ini ditolak oleh Abu Husein an-Nuri yang menganggap tasawuf hanya ada pada ajaran Islam karena tasawuf adalah ajaran untuk pasrah kepada Tuhan, yaitu Allah, bukan Tuhan yang lain. Abu Husein anNuri mengatakan "ketika mereka meninggalkan apa-apa selain Allah, jadilah mereka orang yang tidak memiliki dan dimiliki." (Anwar, 2009: 15).

Al Ghazali mengajarkan untuk menghormati orang kafir (al Ghazali, 1997: 11), namun al Ghazali melarang seseorang untuk menjadi kafir, karena kufr menurut al Ghazali adalah penyakit hati yang harus dibersihkan karena dapat membuat hati seseorang menjadi mati. Selain kufr, penyakit hati yang lain adalah munafik, fasik, kema'siatan, dan bid'ah (Hawwa, 2007: 199-202).

Kufr harus dihilangkan (takhallî) dari manusia, karena penyakit hati itu akan menghalangi manusia untuk menyucikan jiwa (tazkiyah al nafs). Kufr merupakan perbuatan melanggar syari'at yang sudah sangat jelas dan akan menggugurkan kalimat syahadat yang telah diucapkan, karena kufr merupakan kegelapan yang menyebabkan setiap perbuatan tidak bermanfaat (al Ghazali, 1996: 240).

Secara definitif, al Ghazali menjelaskan bahwa yang dimaksud dengan kufr adalah pengingkaran terhadap Rasulullah SAW. dan ajaran-ajaran yang dibawanya, sedangkan iman (lawan $k u f r$ ) adalah mempercayai segala bentuk ajaran yang dibawanya. Oleh karena itulah, Yahudi dan Nashrani termasuk orang kafir karena mengingkari kerasulan Nabi Muhammad SAW. dan ajaranajaran yang disampaikan (al Ghazali, 1996: 239).

Jika dihubungkan dengan konsep tasawuf Schimmel yang mengatakan bahwa semua orang yang mengerti dan mengajarkan tentang kesadaran terhadap Kenyataan Tunggal, kearifan, Cahaya, dan Cinta, dapat dianggap sebagai sufi, maka ini harus dikritisi kembali. Karena tasawuf bukan hanya sekedar ajaran mistik saja, melainkan juga metode penyucian jiwa agar tercapai kondisi taqarrub bi Allâh (Hawwa, 2007: 199-202).

Kepercayaan terhadap Allah sebagai Tuhan dengan segala aturanNya (syari'ah) menjadi salah satu kunci dalam bertasawuf, artinya tasawuf sebagai ajaran yang muncul dari Islam menuntut para penganutnya untuk beragama Islam, karena hanya agama Islam yang mempercayai Allah dengan segala ajaran-Nya yang disampaikan melalui Rasul-Nya. Ini menunjukkan bahwa yang disebut sufi bukanlah seseorang yang sekedar hidup sederhana, berbaju compang-camping, kumuh, lusuh, miskin, dan memiliki kesadaran 
terhadap Kenyataan Tunggal, kearifan, Cahaya, dan Cinta saja, melainkan dia juga harus seorang muslim, karena tasawuf memiliki konsepsi tersendiri, setidaknya seperti yang disampaikan al Ghazali dan Abu Husein an-Nuri (Al Ghazali, 1996: 239).

Menurut Amin Syukur, "kajian Schimmel tentang tasawuf hanya sebatas historisitas, mengulas aspek luarnya saja" (Kuliah "Sejarah Pemikiran Tasawuf," Sabtu, 23 Juni 2012). Mungkin hal itu disebabkan oleh basic pendidikan Sejarah Agama-Agamanya yang juga mewarnai alur berpikirnya ketika melihat tasawuf (Haskins, 1993: 7-9). Sebagaimana lumrah diketahui, bahwa dalam mempelajari Sejarah Agama-Agama bukan berarti harus melebur dalam berbagai agama yang sedang dikaji, tetapi cukup mengerti saja. Corak seperti inilah yang juga dilakukan Schimmel ketika dia mengkaji dan meneliti tasawuf, dimana ketertarikannya dalam meneliti tasawuf bukan berarti mewajibkannya untuk berpindah keyakinan menjadi Muslim, beralih dari outsider tasawuf menjadi insider tasawuf (sufi/muslim).

Salah satu kelemahan kajian yang dilakukan outsider adalah keterbatasan informasi yang dimiliki. Hal ini juga terjadi pada Schimmel yang terlihat sedikit rancu dalam memaparkan konsep mistik spiritual al Rumi tentang sholat (Schimmel, 2002: 199-211). Pembahasan Schimmel tentang konsep sholat dan doa menjadi tumpang tindih, seolah sama, tetapi juga terkesan berbeda. Memang sholat secara ethimology berarti do'a, namun doa dengan اقوال و افعال مفتتحة بالتكبيرو مختتمة بالتسليم بشـروط (al Husainî, tt: I: 82).

Mungkin ini terjadi karena latar belakang Schimmel sebagai orientalis (outsider) yang memiliki keterbatasan tentang detil keislaman, atau mungkin karena penulisan karya itu sendiri yang diproyeksikan untuk masyarakat Eropa, di mana dalam pemahaman Barat-Kristen, sholat cukup sekali saja, seperti doa. Menyikapi sisi ke-outsider-an Schimmel, ada beberapa pihak yang meragukan obyektifitas kajian tasawufnya. Tim Penerbit Pustaka Sufi, misalnya, mengkhawatirkan Schimmel masih seperti orientalis lain yang belum bisa melihat Islam dari kacamata Islam itu sendiri (Tim Penerbit Pustaka Sufi, 2002: ix). Sementara pendapat berlawanan justru menganggap kajian tasawuf Schimmel telah berjasa membuat pemahaman madzhab-madzhab sufi menjadi tidak bias. Wahid Bakhsh Rabbani juga menganggap sang orientalis protestan ini pantas mendapatkan penghargaan karena kedalaman pengetahuannya tentang doktrin-doktrin sufi (Rabbani, 1995: 222-226).

Sejalan dengan pendapat Wahid Bakhsh Rabbani, berdasarkan 
pengetahuan penyusun dan sejauh beberapa literatur yang pernah dibaca, penyusun berkesimpulan bahwa kajian ketimuran yang dilakukan Schimmel cenderung obyektif. Bahkan tidak jarang dia mengkritisi Barat sendiri yang menurutnya terkadang melihat keislaman (ketimuran) dari aspek yang cenderung menguntungkan Barat saja. Orientalis yang tidak utuh melihat keislaman (ketimuran) itu dipengaruhi oleh latar belakang "biblikal" dan pendekatan "klasik" terhadap keilmuan (Schimmel, 1996: 15).

Selebihnya, Schimmel tidak memiliki rumusan yang jelas tentang tasawuf atau konsep mistik Islam. Meskipun Schimmel pernah menulis buku yang sudah diterjemahkan ke dalam bahasa Indonesia dengan judul "Definisi Tasawuf, Manusia dan Kesempurnaanya, Tharîqah, dan Tasawuf Teosofis," namun tulisan itu bukanlah rumusannya sendiri, melainkan kutipan dari beberapa konsep tasawuf yang ditorehkan beberapa sufi, terutama al Rumi. Artinya, apa yang tertuang dalam tulisan tasawuf Schimmel adalah rangkuman atau tulisan ulang terhadap konsep tasawuf beberapa sufi besar, seperti al Rumi. Tentunya hal ini berbeda dengan al Ghazali yang memiliki rumusan tersendiri tentang tasawauf yang bisa jadi berbeda dengan konsep tasawuf gurunya, Yusuf al Nassaj dan Afdhal bin Muhammad (Dunia, 1971: 18).

\section{Simpulan}

Schimmel hanya melihat tasawuf dari sisi luarnya saja, oleh karenanya dia menganggap tidak perlu masuk Islam meski telah berpuluh-puluh tahun bergelut dengan dunia tasawuf. Apalagi dia menganggap tasawuf sebagai ajaran mistik yang juga ada dalam agama-agama yang lain, seperti Budha dan Shinto. Baginya yang terpenting adalah bisa melaksanakan ajaran yang disampaikan tasawuf (mistik), yaitu kesadaran terhadap Kenyataan Tunggal, Kearifan, Cahaya, dan Cinta, tanpa harus pindah keyakinan teologis menjadi muslim.

Meski Schimmel seorang outsider orientalis, namun jasa-jasanya yang tertuang dalam tulisan tentang tasawuf dapat dijadikan sebagai salah satu referensi yang cukup representatif tentang ketasawufan, karena kajiannya yang mendalam dan cenderung objektif.

\section{Daftar Pustaka}

Ahmad, Zainal Abidin. 1975. Riwayat Hidup al Ghazali. Jakarta: Bulan Bintang.

Anwar, Rosihon. 2009. Akhlak Tasawuf. Bandung: Pustaka Setia. 
Arberry A. J. 2005. Pasang Surut Aliran Tasawuf. Bandung: Mizan.

Arifin, Samsul, dkk. 1996. Spiritualitas Islam dan Peradaban Masa Depan. Yogyakarta: Sippress.

Bagir, Haidar, 2002. Manusia Modern Mendamba Allah. Dalam Ahmad Najib Burhani (ed.), Manusia Modern Mendamba allah: Renungan Tasawuf Positif. Jakarta: Mizan Media Utama.

Baldick, Julian. 2002. Islam Mistik; Mengantar Anda ke Dunia Tasawuf. Jakarta: Serambi.

Burhani, Ahmad Naji. 2002. Pengantar Editor. Dalam Ahmad Najib Burhani (Ed.), Manusia Modern Mendamba Allah: Renungan Tasawuf Positif. Jakarta: Iman dan Hkmah.

Dunia, Sulaiman. 1971. al Haqiqah fi Nazhr al Ghazali. Kairo: Dar al Ma'arif.

Ghazali Al . 1998. Al Munqîdh min al Dhalâl. Trjemahan oleh Achmad Khudori Soleh. Bandung: Pustaka Hidayah.

Ghazali Al . tt. Ihyấ' Ulûm al dîn, Jilid III, Beirut: Dar Al Fikr.

Ghazali Al . 1997. Kaidah-Kaidah Sufistik; Keluar dari Kemelut Tipudaya. Terjemahan oleh Mohammad Luqman Hakiem dan Ahmad Najieh. Surabaya: Risalah Gusti.

Ghazali Al . 1996. Majmû’ah Rasâil al Imâm al Ghazâlî. Beirut: Dâr al Fikr.

Haeri, Syekh Fadhlalla. 2003. Dasar-Dasar Tasawuf, Yogyakarta: Pustaka Sufi.

Haskins, Charles Homer. 1993. A Life of Annemarie Schimmel. Williamsburg: ACLS.

Hawwa, Sa'id. 2007. Tazkiyatun Nafs; Intisari Ihya' Ulumuddin. Terjemahan oleh Abdul Amin, dkk. Jakarta: Pena Pundi Aksara.

Husainî al , Taqiyuddin Abi Bakr bin Muhammad. tt. Kifâyah al ahyârfi Halli Ghâyah al Ikhtishâr, Surabaya: Dâr al Kitâb al Islâmî. 
Khan, Hazrat Inayat. 2002. The Heart of sufism, alih bahasa Andi Haryadi, Bandung: PT. Rosdakary.

M., Saini K. 2005. Mengapa Puisi Sufi? Dalam Annemarie Schimmel, Menyingkap yang Tersembunyi: Misteri Tuhan dalam Puisi-Puisi Mistis Islam. Bandung: Mizan.

Mason, Herbert. 2002. Hallaj dan Madzhab Sufisme Baghdad. Dalam Leonard Lewisohn, Warisan Sufi: Sufisme Persia Klasik, dari Permulaan hingga Rumi. Terjemahan oleh Gafna Raizha Wahyudi. Yogyakarta: Pustaka Sufi.

Musthofa, H.A. 2002. Akhlak Tasawuf. Bandung: Pustaka Setia.

Lewisohn, Leonard. 2002. Warisan sufi: Sufisme Persia Klasik, dari Permulaan hingga Rumi Terjemahan oleh Gafna Raizha Wahyudi. Yogyakarta: Pustaka Sufi.

Rabbani, Wahid Bakhsh. 1995. Islamic Sufism: The Science of Flight in God, with God, by God and Union and Communion with God also Showing the Tremendeous Sufi Influence on Christian and Hindu Mystics and Mysticism. Kuala Lumpur: Zafar.

Schimmel, Annemarie. 1997. Islam $\mathcal{E}$ World Peace; Explanation of A Sufi, alih bahasa Su'aidi Asy'ari. Bandung: Pustaka hidayah.

Schimmel, Annemarie. 1996. Kata Pengantar. Dalam Sachiko Murata, The Tao of Islam: A Source Book on Gender Relationship in Islamic Thought. Terjemahan oleh Rahmani Astuti dan M. S. Nasrullah. Bandung: Mizan.

Schimmel, Annemarie. 2000. Dimensi Mistik dalam Islam. Terjemahan oleh Sapardi Djoko. Jakarta: Pustaka Firdaus.

Schimmel, Annemarie. 2002. Dunia Rumi: Hidup dan Karya Besar Penyair Sufi, alih bahasa Saut Pasaribu. Yogyakarta: Pustaka Sufi.

Schimmel, Annemarie. 2005. Menyingkap yang Tersembunyi: Misteri Tuhan dalam Puisi-Puisi Mistis Islam. Bandung: Mizan.

Syukur, M. Amin. 2012. Menggugat Tasawuf. Yogyakarta: Pustaka Pelajar.

Syukur, M. Amin. 2004. Tasawuf sosial. Yogyakarta: Pustaka Pelajar.

Syukur, M. Amin. 1997. Zuhud di Abad Modern. Yogyakarta: Pustaka Pelajar. 